\title{
Condiciones sociales, culturales y económicas de las maras en Centroamérica. Un estudio comparativo: jóvenes y violencias en Bogotá*
}

\author{
Social, cultural and economic conditions of the maras. \\ A comparative study: violence and youth in Bogota \\ Condições sociais, culturais e econômicas de gangues. \\ Um estudo comparativo: juventude e violência em Bogotá
}

Revista LOGOS CIENCIA \& TECNOLOGÍA ISSN 2145-549X

Vol 3. No. 2, Enero-Junio, 2012, pp. 10-21

\section{Resumen}

Este proyecto se ocupó de analizar las condiciones sociales, económicas y culturales favorables a la presencia y desarrollo de agrupaciones con características de maras en Bogotá. Debido a esto, se incluyen los componentes de la formulación y los resultados de la indagación sobre condiciones dadas en la región centroamericana frente a las correspondientes a Bogotá, sin perder de vista el contexto nacional y regional; y el resultado del análisis de experiencias de intervención que han sido realizadas al respecto.

Palabras clave: Maras, pandillas, jóvenes, Centroamérica, Bogotá, violencia.

Fecha de Recepción: 29 de Noviembre de 2011 Fecha de Aceptación: 3 de Enero de 2012

* Este artículo es producto del Grupo de Investigación de la Escuela de Postgrados de la Policía Nacional de Colombia. INVESPOL-DINAE Análisis y reflexiones desde la academia en campos y áreas a fines al quehacer policial. COL0119146.

** Principal del Grupo de Investigación de la Escuela de Postgrados de la Policía Nacional de Colombia.

\begin{abstract}
This project deals with analyzing the social, economic and cultural conditions favorable to the presence and development of gangs with characteristics of "maras" in Bogota. Therefore, it includes the components of formulation and results of the research about conditions at the Central American region compared to Bogota, without losing sight of national and regional contexts nor the results of the analysis of intervention experiences that have been made in this regard.
\end{abstract}

Key words: "Maras", gangs, youth, Central America, Bogota, violence.

\section{Resumo}

Este projeto está preocupado em analisar a presença social, econômica e cultural e favorecer o desenvolvimento de clusters com características de MARAS em Bogotá. Devido a isso, incluindo os componentes da formulação e os resultados do inquérito sobre as condições dadas na região Centro-Americano confrontados com os de Bogotá, sem perder de vista o contexto nacional e regional, eo resultado da análise de experiências de intervenção que têm sido realizados. 
Palavras chave: Maras, gangues, jovens, central, Bogota, violência.

\section{INTRODUCCIÓN}

El fenómeno de las maras es claramente un problema que ha cobrado carácter transnacional, lo que significa que se ha expandido a otros países de América Latina. En el caso de Colombia, se evidencia un conjunto de condiciones contextuales similares a aquellas que han posibilitado la emergencia de las maras en Centroamérica.

Tanto desde el punto de vista académico como desde la óptica de intervención, y de manera especial para la Policía Nacional de Colombia, es necesario emprender trabajos y acciones de carácter preventivo en medio de un contexto donde han sido legitimadas lógicas y prácticas basadas en la represión, caracterizadas por carecer de actividad reflexiva, analítica y comprensiva, lo cual se traduce en resultados ineficaces y contrarios a lo esperado (es el caso de las equivocadas medidas tomadas en Centroamérica contra las maras). Se hace necesario situar el contexto bogotano como ciudad capital porque se constituye en un referente clave tanto de las dinámicas sociales, culturales y económicas en general, como de las características de la violencia particulares del contexto urbano ${ }^{1}$.

Tras considerar los fuertes impactos de la mediatización de la realidad en la vida cotidiana, es necesario confrontarla con indagaciones profundas que interpelen las afirmaciones que configuran un panorama, en este caso de sensación de existencia de las maras en Colombia o de su inminente aparición. De allí que la investigación plantee los siguientes objetivos: analizar las condiciones sociales, económicas y culturales favorables a la presencia y desarrollo de agrupaciones con características de maras en Bogotá; identificar condiciones sociales, culturales y económicas de las maras en Centroamérica y compararlas con las condiciones actuales del contexto bogotano; y problematizar las estrategias de inter-

Como se especifica en la investigación, las maras corresponden a un fenómeno exclusivamente urbano. vención que se han ejecutado respecto al fenómeno de las maras, principalmente en Centroamérica.

Más allá de la tensión entre la Policía y una "nueva amenaza", es necesario precisar el análisis de las condiciones que posibilitan el desarrollo de expresiones culturales asociadas a la comisión de delitos. Los análisis del crimen y el delito deben abordarse cuestionando sus genealogías sociales e históricas, de manera que se enriquezca la mirada que posibilita las estrategias de intervención y acción.

\section{PROBLEMA DE INVESTIGACIÓN}

\section{Contexto centroamericano}

Las verdades contemporáneas son producto de una construcción social legitimada por los imaginarios y las prácticas que encarnan. Este es el caso de las representaciones constituidas en torno al fenómeno de las migraciones. En el caso de las maras, se produce una reacción creciente que alerta sobre "el peligro" que representan ante una inminente o eventual expansión en otros territorios; de ello son prueba los pronunciamientos de diversos sectores de la sociedad que han advertido sobre el peligro. Sin embargo, los fenómenos delincuenciales de diversa índole solo pueden instalarse o expandirse en lugares cuyas sociedades lo posibilitan.

El Informe sobre Desarrollo Humano para América Central (2009-2010) responde a las siguientes dos preguntas: 1) ¿por qué se forman estos grupos? y 2) ¿qué tan absorbentes son?:

1. Habría tres razones principales para que un joven se vincule a una pandilla: las afectivas, las de seguridad y las utilitarias. Aunque estas razones no se excluyen entre sí, en distintos contextos o momentos predomina una $u$ otra. Algunos estudiosos ven la pandilla como una especie de familia sustituta que satisface las necesidades afectivas del joven, que provee de identidad y dignidad a muchachos marginados y con poca probabilidad de ascender en el orden social convencional; algunos otros acentúan las exigencias de seguridad personal (defenderse de la pandilla del otro barrio, de la Policía o de al- 
gún otro agresor), y otros destacan el propósito de vivir mejor, así sea por medios ilegales. En el contexto centroamericano se habla además del cambio registrado entre la década de 1980, cuando la pandilla se formaba sobre bases afectivas como la solidaridad y el sentido de pertenencia, y la actualidad, cuando predominarían motivos más pedestres, como el acceso al dinero y al poder (Demoscopía, 2007).

2. En el caso de las dos grandes pandillas centroamericanas -la Mara Salvatrucha (MS-13) y la Pandilla de la Calle 18 (o Barrio 18)-, poseen una estética elaborada y unos códigos de ingreso, conducta y disciplina bastante más extensos y exigentes que las pandillas típicas de otras latitudes. En este sentido la pandilla no es una forma de pasar el tiempo sino una forma de vivir

La necesidad de contextualizar el estudio sobre las maras en la comprensión del fenómeno de las pandillas. Carlos Mario Perea, en diversos trabajos, se interroga por la constitución y composición social de las maras, lo cual permite formular distinciones con respecto a ellas sin ignorar las transversalidades implicadas.
(Santamaría, s. f.) -a la cual además no es fácil renunciar por una mezcla de temor a las represalias, pérdida de poder e ingresos, falta de oportunidades y estigmatización social- (Falkenburger $y$ Thale, 2008).

Todo lo anterior confirma la necesidad de contextualizar el estudio sobre las maras en la comprensión del fenómeno de las pandillas. Carlos Mario Perea, en diversos trabajos, se interroga por la constitución y composición social de las maras, lo cual permite formular distinciones con respecto a ellas sin ignorar las transversalidades implicadas.

Así mismo, resulta claro que las maras antes de serlo fueron pandillas, la historia de su surgimiento no se entendería desligada de tal hecho; esto indica que la formación de pandillas puede derivar en formas más intensas y diversificadas de violencia, lo cual acentúa la necesidad de prestar atención a este fenóme- no. Una pandilla es una "agrupación de muchachos populares urbanos asentados en un territorio bajo la condición del tiempo paralelo" (Perea, 2007). La comprensión de las pandillas, como de las maras, pasa necesariamente por la condición de tiempo paralelo, que indica habitar en una temporalidad simultánea pero distinta a la de los tiempos socialmente establecidos, esto involucra una ruptura con lo instituido.

La primera ruptura fundamental se produce con la familia. Una simplificación al respecto que no puede admitirse es la falsa idea de la "desestructuración familiar" como el factor causante del fenómeno pandillero o marero. Esta toma de distancia con el ámbito familiar que demarca una ruptura institucional no es radical en el sentido en que los pandilleros preservan un referente territorial local que corresponde a la conservación de la pertenencia a un núcleo familiar.

Entrevistados guatemaltecos explicaron que los jóvenes se unen a las pandillas porque no reciben suficiente atención de los miembros de su familia o tienen problemas de comunicación con ellos, lo cual los conduce a buscar confidencia y mejor vida fuera de la familia.

La ruptura con la escuela es la segunda ruptura institucional fundamental. La escuela es un ámbito de socialización que conecta con los flujos de la vida social cotidiana legitimada, al igual como ocurre con la tercera institución en ruptura: el trabajo. Pocos pandilleros preservan su vínculo con la escuela, quienes se salen lo hacen tempranamente, la mayoría tras completar apenas la primaria (Perea, 2007). Lo referente al trabajo es la condición de desocupación o, en el "mejor" de los casos, de informalidad e inestabilidad laboral. Todo ello se va conjugando para presionar, también desde la precariedad de las condiciones socioeconómicas, el ingreso al mundo de la ilegalidad y la violencia.

Una cuarta ruptura completa este cuadro: la participación en lo público. La ausencia de organización y participación alrededor de ideales colectivos que convoquen un interés en la comunidad o en lo público es un aspecto que caracteriza la vida y el 
ethos pandilleros. De hecho, este aspecto sugiere una interesante alternativa de intervención frente al fenómeno de las maras y las pandillas en términos culturales y de participación política: es necesario producir universos de significado que convoquen en torno a ideales y finalidades que preserven los flujos con la vida social, pero que permitan en todos los casos una expresión pacífica de protesta contra la pobreza y la exclusión. La participación en la vida pública con fines comunitarios inserta a los individuos en otras lógicas y prácticas de convivencia ciudadana.

Así, la protección y la transgresión son elaboraciones nucleares en la conformación de la cotidianidad de las pandillas. La protección es una necesidad construida y validada a su vez mediante la transgresión, lo cual implica dos dimensiones fundamentales: las prácticas conflictivas y la entrega a la experiencia colectiva; ambas se encuentran en una relación de mutua dependencia. La membrecía a la pandilla no significa solo búsqueda de protección: acude a la violencia, a la agresión y a la transgresión, que posibilitan la territorialidad, el miedo y el respeto.

Ahora bien, desde el punto de vista sociológico, es necesario precisar otras variables que conforman un escenario transversal que trasciende la singularidad de las pandillas y las maras a la vez que las sitúa cultural y socioeconómicamente en su especificidad.

Así, un primer aspecto es la territorialidad, que conforma un universo simbólico y material para el ejercicio de la actividad colectiva de las pandillas y maras. El barrio, "la clica" o la zona, es la unidad territorial de referencia que vincula al imaginario de identidad de las pandillas y las maras. De hecho, en el caso de las maras estuvieron definidas desde sus orígenes así: Mara 18 y Mara Salvatrucha 13, denominaciones ligadas a las calles de referencia territorial de gangs en Los Ángeles (18th Street y 13th Street), que anteceden la experiencia del despliegue de las maras en Centroamérica.

Pero esta territorialidad, ¿por parte de quiénes es ejercida? Edad y sexo son variables sociodemográficas que permiten especificar, en el caso de las pandillas y las maras, una identidad fundamentalmente asociada a jóvenes varones, más allá de los casos excepcionales y minoritarios ${ }^{2}$. Estos jóvenes pertenecen a sectores populares cuya condición socioeconómica es precaria. Nótese en lo que hasta aquí se ha señalado que no se trata de la simplificadora ecuación "pobreza = violencia" (como tampoco lo es "jóvenes = violencia"); en su lugar, ocurre que la carencia de condiciones materiales para la vida digna opera como un ingrediente que potencia el malestar: los jóvenes de las clases populares sufren de altos niveles de exclusión tanto en Centroamérica como en Colombia.

Finalmente, no puede perderse de vista que la violencia de las pandillas y las maras tienen un carácter urbano. En zonas rurales no hay presencia de ellas, ni en Centroamérica ni en Bogotá. Las denominadas "guerras de pavimento" son el sello distintivo del trasfondo contextual que producen estas dinámicas. Todas las dimensiones señaladas son constitutivas del fenómeno de las pandillas y las maras.

Un primer aspecto es la territorialidad, que conforma un universo simbólico y material para el ejercicio de la actividad colectiva de las pandillas y maras. El barrio, "la clica" o la zona, es la unidad territorial de referencia que vincula al imaginario de identidad de las pandillas y las maras.

Ahora bien, cuando se trata de precisar la presencia diferenciada de maras y pandillas en Centroamérica, se llega a conclusiones relevantes. Una de ellas es que se está ante un fenómeno que no se encuentra determinado por una sola constante, sino que se posibilita por la conjugación particular de diversas variables en un contexto determinado. Las maras se han extendido a algunos países de Centroamérica y

\footnotetext{
Es el caso de los jefes de estas agrupaciones que se preservaron como parte de la comunidad de maras, incluso estando tras las rejas (Perea, 2007) y traspasaron los límites de la condición de jóvenes. También es el caso de las mujeres pandilleras y mareras, quienes aunque asumen un rol fundamental en las agrupaciones que está aún por establecerse en toda su magnitud, no conforman la población mayoritaria en el interior.
} 
no a otros, pese a sufrir también de condiciones de pobreza y exclusión social.

\section{Maras en el escenario internacional}

Dada la multiplicidad de países vinculados al fenómeno, y como resultado de esta investigación, llevamos a cabo una búsqueda que derivó en la clasificación de cuatro grupos ${ }^{3}$. Desde el Grupo 1, en donde están los países en que las maras operan abiertamente, hasta el Grupo 4, donde está el extremo de los "mitos" al respecto.

En el periodo de búsqueda de información, se halló una multiplicidad de referentes que hablaban de la colonización del mundo por parte de las maras; así, se encontraron referencias a la presencia de maras incluso en países como los indicados en el Grupo 4. Sin embargo, esto corresponde más a los mitos y leyendas urbanas que se tejen con imagina-

El fenómeno de las
maras es producto de
situaciones extremas
de exclusión y
marginación social,
política y económica,
en un contexto de
conflictos, violencias
y de guerra. ¿Podría
darse entonces el
fenómeno de las
maras en Bogotá?
rios infundados. Por otra parte, para cuatro países de Centroamérica: Costa Rica, Nicaragua, Belice ${ }^{4}$ y Panamá, con dos países suramericanos, Colombia entre ellos, se encuentra algún tipo de referencia sobre la presencia de mareros, aunque la realidad sean las pandillas y el mito sean las maras. En el Grupo 2, se encontró solo un país centroamericano, México, y dos por fuera de Latinoamérica: Estados Unidos y España. A diferencia de los demás grupos, en estos países sí se evidencia presencia de mareros, y aunque su presencia es marginal-cosa que es

3 Grupo 1: Guatemala, El Salvador y Honduras; Grupo 2: México, EE. UU. y España; Grupo 3: Costa Rica, Nicaragua, Belice, Brasil, Panamá y Colombia; Grupo 4: Canadá, Australia, Alemania, Japón, Bolivia.

4 Belice es un caso singular, ya que corresponde a Centroamérica en términos geográficos pero no términos culturales; es un país anglosajón donde no ha tenido presencia el fenómeno de las maras aunque sí registra pandillismo. imprescindible no perder de vista-, predomina otro tipo de pandillas por encima de ellas. Finalmente, la realidad de las maras, que se expresa con fuerza, se concentra en el Triángulo del Norte ${ }^{5}$.

Según Santamaría (s. f.), son múltiples las condiciones que hacen que los países del Triángulo del Norte presenten un clima propicio para la proliferación de las dos grandes confederaciones de maras (M13 y M18). Uno de los factores identificados ha sido el proceso de desmilitarización abrupta y los vacíos de poder, en términos de instituciones de procuración de justicia que trajo consigo la transición de la guerra a la paz.

Finalmente, es claro que el fenómeno de las maras es producto de situaciones extremas de exclusión y marginación social, política y económica, en un contexto de conflictos, violencias y de guerra. ¿Podría darse entonces el fenómeno de las maras en Bogotá?

\section{Caso Bogotá}

Al caso colombiano le corresponde un contexto de guerra, pues se trata de un conflicto social armado de larga duración que ha generado fenómenos como el desplazamiento interno, y en lo que concierne a los actores armados, se han producido desmovilizaciones y reinserciones, además de bandas "emergentes" que derivan de la reorganización del crimen 6 .

Nótese que en el estudio de las maras en Centroamérica no puede omitirse el caso de Guatemala, el cual conforma parte del denominado Triángulo del Norte.

6 Respecto al conflicto interno en Colombia, el contexto puede compararse con el caso costarricense. Según el GERN, "Hacia 1979, la violencia entre el gobierno y la oposición degeneró en una guerra civil", aunque el conflicto armado nunca fue declarado en forma oficial. "El principal resultado de esta investigación en cuanto a la diferencia de Costa Rica con otros países de la región, consiste en evidenciar que el trasfondo histórico de ambas sociedades es diametralmente opuesto en lo que se trata de violencia estructural. La guerra civil de Costa Rica, y las secuelas de su institucionalización, no puede compararse con el trauma social del inconsciente colectivo de otras sociedades centroamericanas". Sin embargo, una de las lecciones de la experiencia costarricense es que las guerras se producen de manera contextualizada, y en tal sentido generan un complejo de singularidades históricas, lo cual indica que la enunciación de la condi- 
Con respecto a la pobreza, cabe señalar que Colombia ocupa uno de los primeros lugares a nivel latinoamericano, incluso con la particularidad que presenta Bogotá en términos de la superación de la pobreza y la miseria en porcentajes sorprendentes los últimos años.

En relación con la escolarización, Bogotá presenta una segunda excepcionalidad a nivel nacional: hay una tasa de cobertura total en lo que se refiere a la educación primaria y secundaria. Ello demarca una seria condición en contra de la proliferación del pandillismo en Bogotá, y por tanto resulta desfavorable para pensar la implantación de las maras en la ciudad.

Con respecto a la familia, los datos a nivel nacional son preocupantes en cuanto a violencia familiar, infantil y de pareja se refiere. Según la información obtenida de las bases de datos de dictámenes sexológicos del Instituto Nacional de Medicina Legal y Ciencias Forenses en su publicación del año 2009, el número de personas menores de 18 años que fueron violentadas sexualmente en el marco de la violencia intrafamiliar fue de 6490, y la diferencia porcentual entre mujeres y hombres fue significativa $(85 \%$ y $15 \%)$.

Con el tema del trabajo, hay un asunto que debe distinguirse: si se habla de juventud y no solo de jóvenes, en términos de la moratoria social es necesario precisar que no corresponde suponer la "empleabilidad" en cuanto a los jóvenes. El lugar de los niños y los adolescentes es la escuela, no el trabajo. La dimensión laboral concierne de modo directo a los jóvenes en lo que se refiere a las condiciones económicas y laborales de los adultos cabeza de familia.

Respecto a los adolescentes en conflicto con la ley, de un total de 3601 casos, estas cifras indican que para el año 2009, el principal delito de los adolecentes es el hurto, con un registro de 2087 casos. El tráfico de estupefacientes registra 663 casos, el homicidio reporta 56 casos y la fabricación, tráfico

ción de guerra no es una evidencia por sí misma de la potencial presencia de las maras en otro país. y porte de armas de fuego o municiones reporta 92 casos (con una disminución de 52 casos respecto al año anterior). Por otra parte, nótese que la extorsión no ocupa un lugar relevante, lo que sí hace en la caracterización de las maras que incurren en extorsiones, principalmente a tenderos y conductores del servicio público. Al observar algunas de estas cifras enlazadas con la revisión de los casos centroamericanos, se relativiza en la indagación más profunda la conexión con el narcotráfico: las mafias y redes de narcotraficantes constituyen una forma organizativa, económica y cultural radicalmente distinta a la de las maras y las pandillas.

De acuerdo con el investigador Carlos Mario Perea, en Colombia no estarían dadas las condiciones suficientes para la implantación del fenómeno de las maras. Uno de los argumentos más importantes al respecto es la hipótesis sobre las "fuerzas de contención", ya que en Colombia la multiplicidad
De acuerdo con el investigador Carlos Mario Perea, en Colombia no estarían dadas las condiciones suficientes para la implantación del fenómeno de las

maras. de actores del conflicto (grupos armados como las guerrillas, los paramilitares, las pandillas) operaría como impedimento a la instalación o despliegue de las maras. En los casos centroamericanos en que el fenómeno de las maras se produjo, estas fuerzas de contención no existieron.

En referencia a elementos complementarios sobre violencia en general asociada a estos grupos, se encuentra que

Riaño-Alcalá (Lacy y Riaño-Alcalá, diciembre 2006) observa que la violencia entre los jóvenes en Colombia está directamente relacionada con la exclusión social y la invisibilidad de aquellos que vienen de áreas pobres. Dicha juventud tiene una conexión reducida con la sociedad y es excluida de aquellas áreas establecidas y espacios públicos donde generalmente ocurre la interacción social. En su lugar, esta juventud invisible empieza a involucrarse en "prácticas territoriales de protección civil y control", las cuales son, a su manera, una forma de expresar su 
ciudadanía y de establecer una conexión con la comunidad. El objetivo de la violencia, como la emplea la juventud, es afirmar y reforzar su conexión con la comunidad para de este modo visibilizarse. De tal manera, la violencia es usada por jóvenes excluidos como medio de comunicación y participación con una comunidad que de otro modo los ignora. (...) El trabajo de campo en comunidades empobrecidas y socialmente excluidas en Colombia también revela el uso de medidas vigilantes y de violencia como los medios para adquirir justicia.

\section{METODOLOGÍA}

El método adoptado se basó en la abducción y la teoría fundamentada, se utilizó además, el programa para el análisis de información cualitativa AtlasTI correspondiente con este enfoque. El desarrollo metodológico se organizó en dos componentes:

\section{- ANÁLISIS DOCUMENTAL}

Revisión de investigaciones existentes sobre maras, información institucional disponible sobre maras en Colombia, audiovisuales sobre las características sociales, económicas y culturales de las maras en Centroamérica, informes y bases de datos sobre inmigraciones y deportaciones que puedan relacionarse con la "importación" del fenómeno.

A partir del análisis documental y audiovisual, se elaboró un informe sobre la caracterización de las condiciones sociales, económicas y culturales de las maras, se identificaron y se analizaron las condiciones sociales, económicas y culturales actuales de Bogotá, en comparación con las centroamericanas; se revisaron las propuestas de intervención; identificación exhaustiva y revisión de experiencias de intervención frente al fenómeno de las maras, principalmente en Centroamérica, y por último, se analizaron las experiencias identificadas.

\section{- ENTREVISTAS A ESPECIALISTAS Y EXPERTOS}

Así mismo, se consultaron expertos en temas de maras, pandillismo, violencia, delincuencia, consumo de sustancias psicoactivas, y estrategias de intervención y prevención con jóvenes. Se entrevistaron miembros de la Policía Nacional de Colombia que podían aportar información sobre la presencia del fenómeno en Bogotá y sobre las adecuaciones de la propuesta según la pertinencia institucional. Se realizaron entrevistas indirectas o consultas eventuales a altos funcionarios de organismos internacionales que confirman la presencia de maras en Colombia.

\section{RESULTADOS Y ANÁLISIS}

\section{Tipos de intervención ${ }^{7}$ social}

Programas Primarios:

- Están enfocados a la población joven en general; buscan reducir los factores de riesgo y aumentar los factores de protección.

- La capacitación para el desarrollo de aptitudes para tomar decisiones correctas (deserción escolar, consumo de drogas, ingreso a pandillas, etc.).

- Se puede evitar que lleguen al comportamiento criminal.

Programas Secundarios:

- Están enfocados a jóvenes en alto riesgo a quienes incluyen en sistemas de apoyo.

- Sus objetivos son: realizar una evaluación de la comunidad que se va a intervenir e identificar factores de riesgo para los jóvenes; reconocer los prejuicios que impiden un trato realista para ellos, y además identificar posibles soluciones y formar alianzas para llevarlas a cabo.

- Se destaca su primacía eficaz del principio de colaboración comunitaria.

Programas Terciarios:

- Son programas de rehabilitación dirigidos a jóvenes involucrados en la violencia y la delincuencia.

La WOLA realiza una clasificación de programas de intervención con maras y pandillas en función del alcance que tienen. 
- Su visión consiste en que la reducción de la violencia requiere de asesoramiento y apoyo, a veces alternativas de vivienda, servicios sociales, educación y capacitación laboral.

Estos enfoques o niveles de alcance que clasifican los programas de intervención en niveles primarios, secundarios y terciarios se encuentran cruzados transversalmente por dos enfoques: el preventivo y el de control. El enfoque preventivo realiza planes de trabajo para estimular la creación de oportunidades de desarrollo para la juventud, y también acompaña a la población en el proceso.

\section{Aproximación a la política pública en el caso de Centroamérica: manodurismo}

El manodurismo se destaca como un proceso de persecución y detención masiva de jóvenes que pertenecen o parecen pertenecer a las maras. En los 90, las políticas de deportación ${ }^{8}$ persiguieron a todos los inmigrantes que tuvieran antecedentes penales con condenas de más de un año para deportarlos.

En San Salvador, en el 2003, se aprobó la Ley Antimaras, con reformas que endurecían el control de los pandilleros; su vigencia fue de seis meses. Justo nueve días antes de que la ley caducara, la Corte Suprema de Justicia la declaró inconstitucional. Ese mismo día, el Gobierno envió otra propuesta de ley contra las pandillas al Congreso, que de inmediato la aprobó; su vigencia fue de 90 días. Simultáneamente, se envió a la Asamblea Legislativa el proyecto de la Ley Antimaras, que establecía un mayor control y sanciones más severas para los pandilleros. De inmediato, la Policía, apoyada por las Fuerzas Armadas, comenzó a capturar a decenas de pandilleros; sin embargo, el impulso perdió fuerza a los pocos días, cuando la mayoría de los pandilleros fueron liberados por los tribunales debido a falta de evidencia.

En abril del 2004 fue declarada inconstitucional la Ley Antimaras, pero al mismo tiempo se aprobó la

\footnotetext{
$8 \quad$ Ley de Reforma a la Inmigración llegal y Responsabilidad
} del Inmigrante, de 1995.
Ley para el Combate de las Actividades Delincuenciales de Grupos o Asociaciones Ilícitas Especiales. Esta segunda Ley Antimaras y el Plan Mano Dura fueron estrategias altamente represivas, incluyeron detenciones masivas solo por la pertenencia a una pandilla, rebaja de los criterios probatorios y duras condenas.

En el 2005, y tras la presión de diversas organizaciones internacionales, se pone en marcha el Plan Mano Amiga y el Plan Mano Extendida, programas del Plan Super Mano Dura, que tenía la misma tendencia de represión y persecución. El primero, diseñado por la Secretaría de Juventud para orientar a jóvenes "sanos" que viven en zonas de riesgo, se mostró como una estrategia de intervención temprana para evitar que los jóvenes llegaran a incorporarse a las pandillas. Por su parte, el segundo estaría orientado a jóvenes miembros de pandillas que deseen dejar las maras. Sin embargo, ellos se quejaron de la insistencia de la persecución policial y cuestionaron los alcances de los proyectos.

Según David Garland (2005), una de las características de la modernidad tardía es el predominio de políti-

Estos enfoques 0 niveles de alcance que clasifican los programas de intervención en niveles primarios, secundarios y terciarios se encuentran cruzados transversalmente por dos enfoques: el preventivo y el de control. El enfoque preventivo realiza planes de trabajo para estimular la creación de oportunidades de desarrollo para la juventud, y también acompaña a la población en el proceso. cas de control sobre las de previsión; la cultura imperante es la de exclusión y las libertades privadas por encima de la solidaridad y las libertades públicas, así que el caso de Centroamérica y la adopción de medidas de mano dura también está insertado en lógicas de carácter global. Estas lógicas han contribuido a estigmatizar a la juventud de áreas marginales como el arquetipo de delincuencia, pero solo ver la punta del iceberg les impide ver su papel en la exclusión de amplios sectores de jóvenes. 


\section{El impacto de la mano dura}

La privación de la libertad se constituye en el tratamiento a la enfermedad, en el castigo justo por los delitos cometidos, en el sentido de expiación de la culpa, pero la cárcel intensificó el carácter criminal de las maras; por algo a las cárceles se les denomina "escuelas del crimen". Algunos dicen que Super Mano Dura ha tenido éxito en la reducción de las pandillas, pero sus actividades se han vuelto más violentas, han recurrido más al homicidio y al tráfico de drogas y armas. Además, está el impacto negativo, que es el debilitamiento de la legitimidad del accionar policiaco.

Los planes de Mano Dura y Super Mano Dura (El Salvador), Libertad Azul (Honduras) y Escoba (Guatemala) comparten un mismo planteamiento de fondo pues consideran que si logran reducir la actividad de las maras, disminuirán también los índices de la criminalidad. La aplicación de estos planes, para el
Los planes de

Mano Dura y Super

Mano Dura (El

Salvador), Libertad

Azul (Honduras) y

Escoba (Guatemala)

comparten un mismo

planteamiento de fondo

pues consideran que

si logran reducir la

actividad de las maras,

disminuirán también

los índices de la

criminalidad. caso de El Salvador, ha sido decepcionante; en lugar de disminuir, se ha producido un aumento del número de homicidios. Otros de los efectos de la mano dura incluyeron acoso policial a las familias o allegados de los mareros, y hasta se llegó a detener a expandilleros que estaban en programas de rehabilitación. El hecho de pertenecer a una mara se convirtió en el delito de la asociación con fines para delinquir, entonces la persecución utilizó una de las características de las agrupaciones para identificarlos y detenerlos: su sistema de comunicación a través de señales de manos.

Así mismo, la persecución llevó a que las dinámicas de la mara se transformaran, lo cual acentuó sus lógicas criminales e hizo desaparecer sus elementos identitarios, como la ropa, los tatuajes y su presencia en reuniones públicas. El fenómeno marero se invi- sibilizó y reforzó el autoritarismo de su organización interna. Las reglas internas de ingreso, permanencia y salida de las maras se endurecieron para proteger a la agrupación, buscando asegurar la lealtad interna. Así, los rasgos simbólicos se diluyeron y los normativos se endurecieron. Las maras han reaccionado ante la persecución y en lugar de desaparecer, se han trasformado, cohesionándose más en la invisibilización.

Además, el cuidarse de un enemigo común (los organismos de seguridad del Estado) las dota de una mayor cohesión, de una significación más fuerte del "nosotros", pues la persecución por parte de un enemigo mantiene y refuerza la lógica marera que construye identidad en la confrontación y el conflicto.

La intervención policiaca refuerza la forma en que la mara construye su identidad a través de la confrontación, el conflicto y la negación del otro. Una intervención efectiva debe considerar cómo la cohesión e identidad de agrupaciones violentas puede ser utilizada en el diseño de estrategias de intervención, ya que la hipótesis consiste en que reforzar los aspectos culturales e identitarios del grupo le quita fuerza a su faceta criminal. En todo caso, la simple represión significa actuar bajo la misma lógica de violencia en la que actúan las maras, lo cual refuerza su conflictividad. La relación entre las partes en conflicto no se repara, sino que se une por medio de la represión y el castigo.

Tras considerar los efectos de este tipo de políticas, se observa que es un grave error basar la intervención en la simple represión. Esta requiere de un enfoque amplio de la mano de la cooperación transnacional y el entendimiento de matices de la realidad de cada país. En este sentido, la WOLA ${ }^{9}$ considera que la reforma policial es un elemento central en el tema de los derechos humanos y la seguridad pública en Centroamérica.

\section{CONCLUSIONES}

Una vez realizada la investigación, lo que se califica como el riesgo o la "amenaza" inminente de las

$9 \quad$ Oficina en Washington para Asuntos Latinoamericanos. 
maras en Colombia queda desvirtuado. Las condiciones dadas en Colombia y en Bogotá no resultan del todo favorables para la implantación y presencia del fenómeno de las maras. La comparación de las condiciones sociales, culturales y económicas de Centroamérica arroja conclusiones sorprendentes: si bien coinciden en la presencia de problemáticas de violencia urbana, de maltrato intrafamiliar, de pobreza y miseria, de guerra (en el contexto colombiano), y en variantes de tipo cultural e incluso del mismo conflicto que se vive en el interior del país, genera fuerzas de contención que harían inviable la instalación o consolidación del fenómeno de las maras.

En su lugar, una de las conclusiones más importantes de este trabajo apunta a la necesidad de centrar esfuerzo de comprensión y análisis que formulen mejores estrategias de intervención con enfoque preventivo en el caso de un fenómeno "connatural" a las maras: el pandillismo. La degradación de las condiciones de vida conduce a una suerte de agudización de la violencia que puede expresarse en formas diversas en cada contexto. En algunos países de Centroamérica fueron las maras, pero en Bogotá y en Colombia, el fenómeno no tiene que adquirir esa denominación para resultar inquietante y digno de la atención debida.

\section{La experiencia centroamericana de las maras deja en claro que}

- Las condiciones contextuales varían de un país a otro y de una ciudad a otra.

- Las formas de organización de las maras significan un fenómeno que se distingue del crimen organizado, tal como es propio de, por ejemplo, las mafias del narcotráfico.

- Las experiencias más represivas son justo aquellas que dejan los resultados menos deseables; la experiencia nicaragüense, en cambio, aporta un ejemplo de atención preventiva y de intervención frente a las maras y también frente al pandillismo.

El anclaje cultural es indispensable a modo de horizonte explicativo y de intervención frente a la exis- tencia, conformación y despliegue de las maras y las pandillas, tanto como frente a los imaginarios sociales que construyen una percepción determinada de estos grupos, la cual se traduce en un imaginario de las medidas por tomar, histórica y frecuentemente represivas y reiteradamente equivocadas, agudizadoras de los problemas que les son conexos. Estos imaginarios, normalmente producidos y reproducidos por los medios como actores destacados, conforman parte integrante de los problemas mismos a resolver, esto es, de las preconcepciones, estigmatizaciones y prejuicios por transformar.

$\mathrm{Ni}$ el pandillismo ni las maras responden a un fenómeno unicausal. En ambos casos se encuentran con un conjunto de dimensiones que les están definidamente asociadas pero que vistas de manera untilateral pierden toda capacidad explicativa. Así, las dimensiones abordadas de familia, trabajo, escuela, identidad, cultura, territorialidad y conflicto urbano solo adquieren sentido en una aproximación de conjunto que no pierda de vista los matices ni las variaciones que se expresan en cada caso y contexto.

Tras la investigación, lo que se califica como el potencial riesgo o "amenaza" de las maras en Colombia queda desvirtuado ante la sola afirmación genérica de contar con el "caldo de cultivo" necesario. Como se señaló anteriormente, las condiciones dadas en Colombia y en Bogotá no resultan del todo favorables para la implantación y presencia del fenómeno de las maras, lo cual matiza y pone en cuestión esa premisa inicial.

Sin embargo, comprender el fenómeno de las maras implica indefectiblemente el estudio del fenómeno de las pandillas. Ello no equivale a eliminar el re- 
conocimiento de las diferencias y singularidades de cada una, sino a indicar que subyace un tejido común de complejidades de orden social, económico y cultural que las configura y les da cuerpo.

el fenómeno de
las maras implica
indefectiblemente el
estudio del fenómeno
de las pandillas. Ello
no equivale a eliminar
el reconocimiento
de las diferencias y
singularidades de
cada una, sino a
indicar que subyace
un tejido común de
complejidades de orden
social, económico
y cultural que las
configura y les da
cuerpo.

En el análisis comparativo, el caso de Bogotá presenta variaciones importantes frente al caso de Colombia. En la capital, se expresan matices significativos en asuntos como la pobreza y cobertura educativa, en los que cuenta con tasas inferiores a las registradas a nivel nacional. Ello indica desafíos para el país como para Bogotá, puesto que se debe avanzar en la eliminación de las más agudas problemáticas sociales y económicas, en términos de mejorar las condiciones prevalentes de precariedad para una parte importante de sus ciudadanos.

\section{Conclusiones de la problematización de las es- trategias de intervención}

- La aplicación de las políticas de mano dura resultó en la transformación negativa del fenómeno de las maras, quienes se invisibilizaron suprimiendo sus signos identitarios y estéticos, y agudizaron su faceta criminal.

- Una estrategia basada solo en la represión descontextualiza los fenómenos y no ataca sus causas.

- Los programas de intervención han demostrado ser más eficaces y rentables que los represivos.

- Los programas de intervención deben construirse conjuntamente con personajes que tengan experiencia propia en el asunto (expandilleros). Los miembros de pandillas les reconocen autoridad y legitimidad.

- La represión policiaca resulta en un afianzamiento de la identidad de las maras, pues refuerza la lógica de construirse en relación con el conflicto.

- La prevención es más barata (social y económicamente) y más eficaz que las medidas represivas.

- Los medios de comunicación tienen un papel fundamental para evitar que continúe incrementándose la imagen de acentuada violencia de las maras y pandillas, y no contribuir a que se constituyan en chivo expiatorio de la violencia urbana. Es uno más de una multiplicidad de actores de las guerras de pavimento, en un contexto de violencia social.

\section{REFERENCIAS BIBLIOGRAFÍCAS}

ARANA, Ana. (2005, julio-septiembre) Cómo las pandillas invadieron América Central. En: Foreign affairs en español, Vol. 5, N. ${ }^{\circ}$ 3, s. l., pp. 116-130.

BERGER, Peter y LUCKMANN, Thomas. (1975) La construcción social de la realidad, Madrid: Amorrotou Editores.

BODEMER, Klaus et al. (edits.) (2001). Violencia y regulación de conflictos en América Latina, Caracas: Adlaf, Heinrich-Boell Stiftung, Nueva Sociedad.

CAÑAVERAL, Snyder y CHRISTINA, Andrea. (2007). Inmigración, transnacionalismo y pandillas: la Mara Salvatrucha. Tesis Magíster en Estudios Latinoamericanos, Facultad de Ciencias Sociales, Bogotá: Pontificia Universidad Javeriana.

DEMOSCOPÍA. (2007). Maras y pandillas, comunidad y policía en Centroamérica. Hallazgos de un estudio integral [en línea], Guatemala: ASDI, BCIE. Disponible en <http://www.pnud.org.gt/data/publicacion/ Maras\%20y\%20pandillas, $\% 20$ comunidad $\% 20$ y\%20polic\%C3\%ADa\%20en\%20centro\%20 am\%C3\%A9rica.pdf $>$. 
FALKENBURGER, Elsa y THALE, Geoff. (2008). Maras centroamericanas: Políticas públicas y mejores prácticas, Washington: WOLA, pp. 45-66.

GARLAND, David. (2005). La cultura del control, Barcelona: Gedisa.

MARTÍNEZ VENTURA, Jaime. (2005). Una aproximación al fenómeno político criminal que representan las "maras" (respuestas actuales a la violencia de las pandillas en la República de $\mathrm{El}$ Salvador. Logros, dificultades y desafíos). En: Cuadernos de Doctrina y Jurisprudencia Penal, vol. 10, nos. 18-19, s. l.

PEREA, Carlos Mario. (2007). Con el diablo adentro. Pandillas, tiempo paralelo y poder, México: Siglo XXI.

PNUD. (2010). Informe sobre Desarrollo Humano para América Central, s. l. Disponible en Internet <http:// economiccluster-lac.org/index. php?option $=\mathrm{com}_{-}$ content\&view $=$ article\&id $=170 \&$ ltemid $=56 \&$ lang $=$ es $>$

POLICÍA NACIONAL DE COLOMBIA. (2007). Lineamientos generales de política para la Policía Nacional de Colombia, Bogotá: DIPON.
LACY, Susan y RIAÑO-ALCALÁ, Pilar. (2006, diciembre). Medellin, Colombia: Reinhabiting Memory. En: Art Journal [en línea], vol. 65, no. 4, s. l., pp. 96-112. Disponible en <http://www.swfs.ubc.ca/fileadmin/ template/main/images/departments/social_work/ faculty/PDF-ilar/2006_MedellinReinhabitingMemory.pdf $>$.

SANTACRUZ GIRALT, María. (2005, noviembre) Creciendo en El Salvador: una mirada a la situación de la adolescencia y juventud en el país. En: Estudios Centroamericanos, nos. 685-686, s. l., pp. 1079-1099.

SANTAMARÍA, Gema. (s. f.). Las maras centroamericanas, una identidad que ha dejado de tatuarse: posibles lecciones para las pandillas mexicanas [en línea], México: Instituto Tecnológico Autónomo de México (ITAM). Disponible en <http://www.insumisos.com/lecturasinsumisas/Las\%20Maras\%20Centroamericanas.pdf $>$.

ZÚÑIGA, Mario. (2010). Acercamiento a los estudios sobre pandillas en América Latina, s. l., Grupo de trabajo Juventud y Nuevas prácticas Políticas en América Latina, CLACSO. 